\title{
Da modernidade em Walter Benjamin: crítica, esporte e escritura histórica das práticas corporais*
}

\author{
Alexandre Fernandez Vaz**
}

\begin{abstract}
RESUMO
Neste texto ocupo-me de alguns aspectos da teoria da modernidade e da filosofia da história de Walter Benjamin, tendo como ponto de fuga a presença do esporte e algumas possíveis contribuições/implicações para uma escritura crítica de sua história. Para isso tomei como referência central duas das principais obras do Autor, A obra de arte na era de sua reprodutibilidade técnica e sobre o conceito de História. Do primeiro texto analiso a concepção de obra de arte, sua reprodutibilidade moderna e sua relação com o esporte, além de fazer alguns comentários sobre a posição do corpo na crítica de Benjamin ao futurismo. Do segundo texto analiso aspectos da filosofia da história de Benjamin. Por fim, problematizo algumas questões para a historiografia da Educação Física/Ciências do Esporte, que dizem respeito a um conceito de história que deve levar em conta a dialética entre progresso e regressão.

Palavras-chave: Benjamin, História do Esporte, Filosofia da História.
\end{abstract}

\begin{abstract}
In this paper, I report the research results on Walter Benjamin's Philosophy of History and its possible contributions to a Sports history. Two essays were specially analysed, Das Kunstwerk im Zeitalter seier techische Reproduzierarkei and Über den Begriff der Geschichte. From the first one, the following are shown: some aspects of Benjamin's Futurism criti-

* Uma versão mais sintética deste texto foi apresentada no VII Congresso Brasileiro de História da Educação Física, Esporte, Lazer e Dança, em Gramado, RS, em 30/05/2000, com o título de Em favor da memória, contra o esquecimento: História, progresso e esporte em Walter

** MEN/CED/UFSC - Universität Hannover/CAPES. Proc. 1106/95-15. alexfu@ex-
\end{abstract} Benjamin (VAZ, 2000). cite.com 
cism and its body consideration. From the second one some aspects of Benjamin Philosophy are analysed. After that, some history concepts of Sports Scients are debated.

Key-words: Benjamin, Sport History, Philosophy of History, Sport.

\title{
Um colecionador de brinquedos e idéias
}

\begin{abstract}
"O dom de despertar no passado as centelhas da esperança é privilégio exclusivo do historiador convencido de que também os mortos não estarão em segurança se o inimigo vencer. E esse inimigo não tem cessado de vencer." (Walter Benjamin)
\end{abstract}

O marxismo dos anos trinta esteve fortemente marcado por uma concepção teleológica da história, que destinava-lhe o inevitável curso que levaria à sociedade socialista. Essa concepção ganhava fôlego no contexto de alguns fenômenos sociais fundamentais para o século vinte, justo na ante-sala da II Guerra Mundial. Refiro-me aqui à experiência socialista soviética - um dos pólos da Guerra Fria -, à ascensão do fascismo - um dos momentos culminantes do capitalismo -, ao cinema - então expressão máxima da reprodutibilidade técnica da imagem e da obra de arte em geral -, e, finalmente, ao esporte - fenômeno global, de massas e de alto rendimento.

Os movimentados anos trinta assistiram também parte da atribulada trajetória de Walter Benjamin, um dos mais importantes teóricos do século, arqueólogo da modernidade, filósofo da história, teórico da cultura e da arte em suas formas de produção e reprodução, flaneur, outsider, colecionador de brinquedos e idéias, renovador da tradição dialética. Nas palavras de Hannah Arendt, "[...] provavelmente o mais peculiar dos marxistas já produzidos por esse movimento, que, sabe Deus, teve todo tipo de excentricidade."1.

Walter Benjamin nasceu em Berlin no ano de 1892. De uma família de judeus comerciantes abastados, teve uma infância típica daquelas crianças de pequena burguesia alemã: brinquedos, passeios, cuidados de empregados e pouco contato com qualquer tipo de pobreza, algo que só veio a conhecer na idade adulta. Suas recordações infantis foram registradas em diversos textos,

1 ARENDT, Hannah. Walter Benjamin: 1892-1940. In: Men in dark times. Harmondsworth: Pelican, 1973. p. 151-203. 
desde os conhecidos "pedagógicos"2 até o belíssimo Diário de Moscou, passando pelos não menos fundamentais Rua de mão única e infância berlinense por volta de 1900. Recolocam-se ainda numa série de programas de rádio no qual Benjamin, entre 1929 e 1932, narrava histórias infantis, todas reunidas em um volume com o sugestivo título de Esclarecimento para crianças (Aufklärung für kinder $)^{3}$. Nele Benjamin exerceu o que de melhor a pedagogia infantil talvez possa fazer: educar para o livre pensamento.

Todos estes textos são extremamente reflexivos, onde o olhar infantil mas não infantilizado - e o trabalho da memória pessoal assumem caráter metodológico, importante na composição de um percurso intelectual que constituirá uma refinada filosofia da história.

O tema da infância em Benjamin, tão estudado e decantado nas "Ciências da Educação", tem pelo menos um outro significado, mais metodológico, estrutural no seu pensamento. Seja pela rememoração - fundamental para aquele que quer ser capaz de narrar histórias -, seja porque para Benjamin a experiência (Erfahrung) é uma categoria histórica essencial, seja ainda porque as atividades infantis podem estar mais facilmente alheias ao mundo da economia, resguardando-se contra a ordem que impele a todos embarcarem no trem do progresso.

Em vários de seus escritos são lembradas e descritas as brincadeiras e explorações da cidade por uma criança - ele mesmo - e ainda o hábito de colecionar (brinquedos, livros, idéias!), conservado durante toda a vida. Em um sensível ensaio, Susan Sontag relata a adoração de Benjamin por sua enorme biblioteca e o quanto seus livros não eram apenas material de trabalho, mas objetos de contemplação. Além disso,

Ele amava velhos brinquedos, selos, cartões postais e divertidas miniaturizações da realidade, como a paisagem invernal num globo de vidro em que a neve cai quando o agitamos. Sua própria letra era quase microscópica, nunca tendo realizado a ambição, segundo o relato de Scholem, de conseguir escrever cem linhas em uma única folha de papel.[...] Como a caixa na fábula de Goethe, um livro não é apenas um fragmento do mundo, mas é, ele mesmo, um pequeno mundo. ${ }^{4}$

2 Vários textos sobre Educação, juventude e infância, escritos entre 1913 e 1932 foram reunidos no volume Über kinder, jugend und erziehung. Frankfurt: Suhrkamp, 1969.

3 TIEDEMANN, R. (Org.). Aufklärung für kinder: rundfunkuorträge. Frankfurt: Suhrkamp, 1985.

4 SONTAG, S. Introduction. In: BENJAMIN, Walter. One-way street and other writings. Nova York: [s. n.], 1985. p. 19-21. 
Os livros readquirem assim, como os brinquedos, um caráter pleno de ritualidade, um diálogo com o mundo baseado em signos, sintetizado de maneira ímpar, certamente, nos livros infantis 5 .

A crítica radical à sociedade burguesa, refinada durante toda a vida, aparecera já na juventude, antes do contato com o marxismo. O adolescente já discursava de forma contundente contra sua própria classe social, ainda que crítica passasse muito mais pela reprovação adulta daquele mundo juvenil, chamado de "inexperiente"

Benjamin teve uma vida complicada e irregular. Como o flâneur, que tão bem descreveu em seus escritos sobre a Paris do século XIX, foi um solitário, um outsider, figura deslocada mas não excluída, da intelectualidade européia dos anos vinte e trinta. Sempre pretendendo viver como "homem de letras", aspiração de vários membros da pequena burguesia européia da primeira metade do século vinte ${ }^{7}$, Benjamin viu sua vida e sua obra revelarem-se em um fracasso exemplar ${ }^{8}$, que vai desde uma livre docência negada (e com ela a carreira universitária), até amores arruinados, passando por uma complicada relação com o Instituto de Pesquisa Social, de Adorno e Horkheimer. No meio disso tudo, sucessivas sintonias e dissonâncias com o marxismo e o sionismo.

Antes de exilar-se na França em 1933 - onde viveu, com pequenas interrupções, o resto de sua vida, Benjamin visitou, entre dezembro de 1926 e janeiro do ano seguinte, Moscou. Lá viveu duas experiências que lhe seriam singulares; o reencontro com Asja Lacis - atriz e diretora de teatro letã, comunista, por meio da qual conhecera Brecht - e o contato cotidiano com o socialismo real, que balizaria, em grande parte, sua relação com o movimento comunista 9 .

Em Paris Benjamin dedicava-se - além da arte de sobreviver com pou$\cos$ recursos $^{10}$ - à redação do Passagenarbeit (Trabalho das Passagens), tarefa à qual se debruçara já a partir do final dos anos vinte. Com o Passagenarbeit, que permaneceu inacabado, Benjamin pretendia escrever sua ar-

5 BENJAMIN, 1969, op. cit.

6 BENJAMIN, 1969, op. cit.

7 ARENDT, op. cit., p. 157.

8 GAGNEBIN, J. Walter Benjamin: os cacos da História. Tradução: Sônia Salzstein. 2. ed. São Paulo: [s. n.], 1993.

9 As experiências em Moscou estão magistralmente relatadas no belíssimo Moskauer tagebuch (Diário de Moscou). Ver BENJAMIN, Walter. Moskauer tagebuch. Frankfurt: Suhrkamp, 1980.

10 Sobre esse tema e outras informações e interpretações biográficas podem ser consultados, entre outros, o belo texto de Jeanne Marie GAGNEBIN (1999 e 1993), ou ainda o livro de FULD, Werner. Walter Benjamin. Eine biografie. Reinbeck bei Hamburg: Rowohlt, 1990. 
queologia da modernidade, vista pelo seu momento e palco privilegiados, a cidade de Paris, capital do século XIX e capital do capital. Lá aparecem suas galerias, avenidas, objetos e personagens (o flanêur, os transeuntes, as passantes, os escroques, os agitadores, os revolucionários), tal como descritos por seus literatos, sobretudo Charles Baudelaire.

Com a ocupação nazista na França, a situação dos refugiados alemães se complicou muito. Tornaram-se poucas as esperanças de resistir ao nazi-fascismo, principalmente depois do tratado de não agressão assinado em 1939 por Hitler e Stalin.

Deteriorado física e psicologicamente ao ser impedido de atravessar a fronteira franco-espanhola, Benjamin consumiu várias drágeas de morfina que trouxera consigo, já prevendo a alternativa do suicídio. Tratado por Benjamin como um momento pelo qual a modernidade (autodestruidora, autofágica) se realiza, o suicídio $^{11}$ foi o meio pelo qual, na madrugada de 26 para 27 de setembro de 1940, sua vida lhe foi barbaramente arrancada.

$$
\leftarrow \uparrow \downarrow \rightarrow
$$

Nas próximas páginas, ocupo-me da reflexão sobre alguns pontos da filosofia da história de Walter Benjamin, com vistas a contribuir para a escritura de uma história das práticas corporais, em especial do esporte. Meu texto gravita em torno de duas das principais obras do Autor, A obra de arte na era de sua reprodutibilidade técnica (Das Kunstwerk im Zeitalter seier techische Reproduzierarkeit), escrito entre 1935 e 1936 e Sobre o Conceito de História (Über den Begriff der Geschichte), conhecido também como Teses, escrito em 1940. Textos diferentes em muitos sentidos, compunham, no entanto, um mesmo projeto intelectual, escrever uma arqueologia da modernidade.

De A obra de arte na era de sua reprodutibilidade técnica interessam para o presente trabalho alguns aspectos da teoria da arte, sua reprodutibilidade e história material, cuja afinidade eletiva com o esporte é, ao longo do texto, apontada. Destaco ainda, rapidamente, a crítica de Benjamin ao Futurismo, e dentro dela a posição ocupada pelo corpo. Nas Teses encontramos

11 “Os obstáculos que a modernidade impõe ao élan produtivo natural dos indivíduos encontram-se em desproporção com as forças dele. É compreensível que o indivíduo fraqueje, procurando a sorte. A modernidade deve estar sob o signo do suicídio que sela uma vantagem heróica que nada concede à atitude que lhe é hostil. Esse suicídio não é renúncia, mas paixão heróica. É a conquista da modernidade no campo das paixões." BENJAMIN, Walter. A modernidade. In: A modernidade e os modernos. Tradução: Heindrun Krieger Mendes da Silva; Arlete de Brito e Tania Jatobá. Rio de Janeiro: Tempo Brasileiro, 1975. p. 12-13. (Biblioteca Tempo Universitário, 41). 
uma filosofia da história que questiona o progresso como categoria absoluta, polemiza com o historicismo e o marxismo "oficial".

Trato principalmente, portanto, da compreensão de Benjamin sobre arte, técnica e esporte, levantando alguns indicativos de sua filosofia da história, tendo como referência a reprodutibilidade técnica moderna.

Por fim procuro problematizar as questões trabalhadas, num diálogo com aspectos da escritura historiográfica dos esportes, verificando como que, ao que me parece, a filosofia benjaminiana pode com ela contribuir.

\section{Esporte, reprodutibilidade técnica, modernidade}

Benjamin dedicou vários estudos à história da produção e reprodução do material artístico. Um dos principais é A obra de arte na era da sua reprodutibilidade técnica $^{12}$. Atenho-me aqui a apenas algumas das inúmeras questões que este magnífico e controverso texto suscita. As controvérsias se devem sobretudo a uma possível ortodoxia marxista, presente não só nesse mas em outros ensaios da primeira metade dos anos trinta. Esta ortodoxia, representada por um excessivo apego às potencialidades progressistas da técnica, seria tributária da influência de Brecht, ou da simpatia pela então União Soviética, oposição visível ao avanço do fascismo na Europa.

De fato, há no texto um espírito simpático à técnica e suas possibilidades de reprodução, que configurariam à arte novas formas de representação. Por outro lado, permanece a crítica à fetichização da técnica, que já fora feita na década de vinte. A meu ver, muito mais notável nesse ensaio é a ênfase na exigência de politização da arte e de seus produtores, como crítica e resistência ao fascismo e suas formas de manifestação estética. Muito mais que em qualquer outro, esse é o ponto que aproxima Benjamin de Brecht, e de resto, ao marxismo "mais militante". Voltarei a esse ponto quando da discussão do caráter engajado do cinema e da arte em geral em Benjamin e Brecht.

Se a resistência soviética acabou por tornar-se ilusória com o tratado de não agressão assinado por Hitler e Stalin em 1939, que possibilitou a invasão

$12 \mathrm{O}$ texto tem duas versões e várias edições. Baseio-me, aqui, na primeira versão, em sua publicação nas Obras Reunidas (Ver BENJAMIN, Walter. Das Kunstwerk im Zeitalter seiner techinischen reproduzierbarkeit (Erste fassung). In: TIEDEMANN, R.; SCHWEPPENHÄUSER, H. (Org.). Gesammelte Schriften. Frankfurt: Suhrkamp, 1980. 
da Polônia e o início da II Guerra, não seria justo dizer que Benjamin tivesse, na metade dos anos trinta, uma visão ingênua do marxismo tornado ideologia de Estado. Prova disso são as anotações críticas do Diário de Moscou e o fato de Benjamin jamais ter se filiado ao partido comunista.

O ensaio foi escrito para ser publicado na Revista de Pesquisa Social, a cargo de Max Horkheimer, diretor do Instituto de mesmo nome já sediado em Nova York, do qual Benjamin se tornara bolsista. Nele é curioso, mas de forma nenhuma inusitado, o aparecimento do esporte como exemplar, fenômeno que interessa à arqueologia de uma modernidade e suas expressões: à direita, com o fascismo, à esquerda, com o comunismo, ambos enredados com as novas condições técnicas de reprodução, inclusive e principalmente do material artístico.

Essas novas técnicas de reprodução alteram sobremaneira o caráter da obra de arte. Se de alguma forma a obra de arte sempre foi reprodutível, o fato é que a cópia já não é vista como imperfeição ou falsidade, como postulara a tradição platônica. A possibilidade de reproduzir indefinidamente uma obra processo que começara com a xilogravura e atingira seu ápice com o cinema torna obsoleta a idéia de cópia. "A obra de arte reproduzida é, em escala crescente, a reprodução de uma obra de arte construída para ser reproduzida."13

A mudança qualitativa pela qual passa a obra de arte pode, talvez, ser assim resumida: "em suas condições materiais e técnicas modernas, a arte pede duas características que lhe foram essenciais: distanciamento e unicidade. Secularizada, e portanto emancipada de seu valor de culto, a arte aproxima-se dos espectadores, ao mesmo tempo que passa a ser reproduzida com freqüência e exatidão cada vez maiores. Aumenta-lhe, portanto, o valor de exposição. A obra de arte vê perder-se sua aura, essa [...]teia singular de espaço e tempo: uma manifestação única de algo distante, tão perto quanto possa estar." ${ }^{14}$ Altera-se com isso o movimento histórico dentro de uma tradição, que agora diz, ao contrário dos gregos, que os valores estéticos já não são eternos. Ao mesmo tempo que se seculariza, ela se politiza, de forma que o fenômeno das multidões pode, logo a após surgir na cena moderna, ver a si mesmo na tela: comícios, guerras e grandes espetáculos esportivos.

Não é sem enormes consequiências que se desenvolve esse processo. Por um lado a própria percepção humana (historicamente condicionada), sofre inúmeras modificações. As imagens captadas pela câmara e depois remontadas em um nexo de cortes e choques (o que significaria de fato a construção da obra cinematográfica) corresponderiam ao ritmo da cidade moderna, onde

13 BENJAMIN, 1980b, op. cit., p. 442.

14 Ibid., p. 440. 
os sentidos são aguçados pelas novas configurações de espaço e tempo, tal como se lê nos ensaios sobre Baudelaire. "O cinema é a arte correspondente aos mais agudos perigos de vida que hoje vivem os contemporâneos." 15

Se a forma reprodutível da obra de arte é, por excelência, o cinema, é porque nele se constrói a relação estética entre o aparato técnico e o ser humano. Para Benjamin, claramente apoiado em Bertold Brecht, trata-se de entender o desempenho do ator (e das massas) diante das câmaras como um teste - alternativo em relação ao trabalho automatizado - para aferir o rendimento frente ao maquinário.

Fica para um outro momento uma questão: que destino terá encontrado o otimismo de Benjamin - e de Brecht! - sobre o caráter revolucionário do cinema? O debate é extenso mas adianto que, de minha parte, prefiro ser cauteloso quanto a um certo realismo socialista. Digo isso porque tanto a direita quanto a esquerda, o esporte, símbolo da idéia de progresso infinito corporificado em medidas de tempo e espaço, passam a ser tema e objeto da produção cinematográfica.

Seja numa perspectiva comunista, com Brecht, seja sob o prisma do fascismo, com Leni Riefensthal, mas sempre louvando o esporte e as performances humanas, não é surpreendente essa preferência. Ora, o cinema - como imagem em movimento que exclui e inclui, potencializa o olho humano, que educa os sentidos para a experiência moderna, como afirma Benjamin - não poderia prescindir do movimento corporal como um de seus privilegiados temas. Enquanto o esporte trabalha com a idéia de precisão do tempo e do espaço, o cinema relativiza-os. À potencialização do corpo corresponde a potencialização da imagem. ${ }^{16}$

\section{O esporte como teste (Leistungstest)}

Nas notas preparatórias para o ensaio sobre reprodutibilidade técnica, Benjamin tece alguns comentários sobre o esporte e os Jogos Olímpicos ${ }^{17}$.

15 BENJAMIN, 1980b, op. cit., p. 464.

16 Sobre o cinema em Brecht consultar o trabalho de ESPERANÇA, I. O cinema operário na República de Weimer. São Paulo: Unesp, 1993. p. 110-116, principalmente. Sobre Riefensthal conferir, entre outros, o interessante livro de WILDMANN, D. Begehrte Körper: Konstruktion und inszenierung des "arischen" männerkör pers im "Drittenreich". Würzburg: Königshausen \& Neumann, 1998.

17 É preciso considerar que, se parte dos comentários não foi aproveitada nas duas versões do ensino, é porque o Autor talvez tenha querido levar as discussões adiante. Duas hipóteses: ou delas não tinha segurança, ou não as considerava importantes para o contexto do ensaio, naquele momento. De qualquer forma, mas considerando o exposto, vale seguir nesse exercício de analisar as anotações de Benjamin. 
As Olimpíadas de 1936, seriam, conforme indica Susan Buck-Morss ${ }^{18}$, a contraface das Exposés: enquanto em Paris, em 1937, seria visto o mais contemporâneo da indústria, da técnica, da comunicação e da energia, em uma palavra, do progresso, na Alemanha estariam, durante um ano, expostos os corpos fortalecidos (e maquinários, segundo penso).

Em suas anotações, Benjamin compara o esporte e os Jogos Olímpicos com a estrutura científica do taylorismo ${ }^{19}$, antecipando em vinte anos as considerações que, nos anos cinqüenta, a então incipiente sociologia do esporte faria a respeito da relação entre esporte e lógica industrial ${ }^{20}$. Aos movimentos do trabalho e da produção automatizada corresponderiam, até certo ponto, os do esporte, passíveis de pormenorizada análise ${ }^{21}$. Fundamental para o esporte, segundo Benjamin, é seu caráter prescritivo, que subjugaria o comportamento humano a uma severa medição em segundos e centímetros, colocando-o ao nível de uma elementaridade física ${ }^{22}$. As "Olimpíadas são reacionárias" "23, escreve Benjamin nas notas, sem levar, no entanto, essa idéia adiante no ensaio propriamente dito.

Em lugar de sua antiga figuração agonística, que comparava seres humanos entre si, no esporte passa a ser fundamental a concorrência com a máquina que mede o tempo e o espaço. Para Benjamin, o esporte também é uma forma de teste, ainda que a forma desta relação permaneça um pouco ambígüa. Como se lê no ensaio, o esporte seria um teste contra as forças da natureza, mas também contra a máquina, no caso de Paavo Nurmi, exceção que, “[...] como se diz sobre ele, corre contra o relógio." 24 O exemplo de Nurmi também aparece como exemplar nas notas, mas como norma, e não exceção.

É importante voltar a destacar a forte influência de Bertold Brecht, na casa de quem, na Dinamarca, Benjamin redigiu seu ensaio sobre a reprodutibilidade técnica. Talvez também por isso os comentários sobre o esporte per-

18 BUCK-MORSS, S. Dialektik des sehens: Walter Benjamin und das passagen-werk. Tradução: Joachim Schulte. Frankfurt: Suhrkamp, 1967. Original inglês. p. 384-391.

19 Ibid., p. 389-391.

20 Ver, como exemplo, os textos de: Habermas, J. Soziologische notizen zum verhältnis von arbeit und Freizeit. In: PLESSNER, H.; BOCK, H. E.; GRUPE, O. (Org.) Sport und leibeserziehung. Munique: [s. n.], 1967; e PLESSNER, H. Die funktion des sports in der industriellen gesellschaft. Wissenschaft und weltbild, n. 19, p. 262-274, 1956. Para uma pequena história do esporte na Alemanha, consultar o artigo de PILZ, G. Sociologia do esporte na Alemanha. Estudos Históricos, n. 23, 1999. Tradução e notas de Alexandre Fernandez Vaz. Original alemão.

21 BUCK-MORSS, op. cit., p. 389-391.

22 BENJAMIN, Walter. Nota a das Kunstwerk im zeitalter seiner technischen reproduzierbarkeit. In: TIEDEMANN; SCHWEPPENHÄUSER, op. cit., p 1039.

23 BENJAMIN, 1980, op. cit., p. 1040; BUCK-MORSS, op. cit., p. 391.

24 BENJAMIN, 1980, op. cit., p. 450. 
cam virulência no percurso das notas para as versões publicadas. Como se sabe, Brecht era um entusiasta do esporte, como mostram alguns de seus textos e filmes ${ }^{25}$. Talvez por isso, na versão final do ensaio o esporte não apareça, como antes nas notas, para ser duramente criticado.

$\mathrm{O}$ esporte era um tema de especial interesse para Brecht, possibilidade de propaganda e expressão do movimento operário comunista, de documentação - também ficcional - de suas experiências. Mas a Brecht, o esporte, a atuação dos atletas, a relação entre eles e com o público interessavam como categorias, sobretudo na configuração do gestus básico, autêntico da/na representação cênica/cinematográfica.

Se no esporte os atletas desempenham contra o relógio, o aparelho que mede o tempo com precisão, adiante-se aqui que, na Tese 15 Sobre o Conceito de História ${ }^{26}$, o relógio aparecerá justamente como o aparato que representa o tempo homogêneo e vazio, carente de significação e conteúdo histórico. Essa temporalidade linear, como se verá mais à frente, é aquela contra a qual a filosofia da história de Benjamin se dirige.

\section{Estética e política, corpo e destrutividade}

Se o cinema é "o objeto atualmente mais importante daquela ciência da percepção que os gregos chamavam de estética", é porque é capaz de fazer convergir a reprodução em massa e a reprodução das massas, como se lê nas páginas finais do texto sobre a reprodutibilidade técnica ${ }^{27}$.

Desfiles, comícios, espetáculos esportivos, mas principalmente a guerra, seriam eventos absolutamente adaptados ao maquinário que potencializa o órgão da visão. Afinal, ainda que o olho humano possa ver, não pode, como o maquinário que o potencializa, ampliar (e também reverter, distanciar e aproximar) as imagens. Fenômeno pleno de significados, se pensamos que a estetização da política, tal como levada a cabo pelo fascismo, procura, segundo a interpretação de Benjamin (mas não só dele!) impossibilitar as transformações que a dinâmica social suscita. Esses esforços para estetizar a

25 BRECHT, B. Schriften zur politik und gesellschaft (Gesammelte werk 20). Frankfurt: Suhrkamp, 1967. p. 26-30.

26 BENJAMIN, Walter. Über den begriff der geschichte. In: Iluminationen . (Ausgewählte Schriften 1). Frankfurt: Suhrkamp, 1977. p. 259.

27 BENJAMIN, Walter. Sobre o conceito de História. In: ROUANET, S. P. (Org.). Magia e técnica, arte e política: ensaios sobre literatura e história da cultura. 6. ed. Tradução de Sérgio Paulo Rouanet. São Paulo: Brasiliense, 1993. 
política, aos quais Benjamin opõe a necessidade de politizar a arte, convergiriam para a guerra ${ }^{28}$.

Nesse sentido Benjamin citará Marinetti, que pensando na guerra colonial da Etiópia, escreveu que

[...]a guerra é bela, porque graças às máscaras de gás, aos megafones assustadores, aos lança-chamas e aos tanques, funda a supremacia do homem sobre a máquina subjugada. A guerra é bela, porque inaugura a metalização onírica do corpo humano. A guerra é bela, porque enriquece um prado florido com as orquídeas de fogo das metralhadoras. A guerra é bela, porque conjuga numa sinfonia os tiros de fuzil, os canhoneios, as pausas entre duas batalhas, os perfumes e os odores de decomposição. ${ }^{29}$

Em outro texto, Marinetti expressara outra vez, conjugando a metalização onírica, o tratamento que o futurismo reserva ao corpo humano: "nós intentamos a criação de uma espécie não-humana, na qual o sofrimento moral, a bondade do coração, a afeição e o amor, esses venenos corrosivos da energia vital, bloqueadores da nossa poderosa eletricidade corpórea, serão abolidos." ${ }^{\text {," }}$

Se para o futurismo trata-se de, de alguma forma, "livrar-se do corpo", para Benjamin a questão é outra, já que guerra cobra seus tributos em "material humano", em destruição da aura ${ }^{31}$.

Afinal, escreve Benjamin,

[...]nunca houve experiências mais radicalmente desmoralizadas que a experiência estratégica da guerra de trincheiras, a experiência econômica pela inflação, a experiência do corpo pela guerra material e a experiência Ética pelos governantes. Uma geração que ainda fora à escola num bonde puxado por cavalos se encontrou ao ar livre numa paisagem em que nada permanecera inalterado, exceto as nuvens, e de baixo delas, num campo de forças de torrentes e explosões, o frágil e minúsculo corpo humano. ${ }^{32}$

28 BENJAMIN, 1993b, op. cit. p. 194-195.

29 Ibid., p. 195.

30 Citado por BERMAN, M. Tudo o que é sólido desmancha no ar: a aventura da modernidade. Tradução de Carlos Felipe Moisés e Ana Maria L. Ioratti. São Paulo: Cia. das Letras, 1992. p. 25.

31 BENJAMIN, 1993, op. cit., p. 196.

32 BENJAMIN, 1993, op. cit., p. 115; 1977, op. cit., p. 291/385-386. Também ADORNO, T. W. Minima Moralia: reflexionen aus der beschädigten leben. GS, v. 4. Frankfurt am main: Suhrkamp, 1997, em suas amargas reflexões foi sensível à questão do encolhimento da Experiência: "Já na guerra anterior, a inadequação do corpo humano às batalhas entre máquinas tornavam impossível a experiência propriamente dita. [...] A Segunda Guerra, [...] está tão distante da experiência quanto o funcionamento de uma máquina dos movimentos do corpo humano, o qual só em estados patológicos se assemelha àquele. Assim como a guerra não contém continuidade, história, nem um elemento 'épico', mas, de certa maneira, recomeça em 
Em última análise trata-se de reservar ao corpo a possibilidade de manter-se como capaz de experenciar (erfahren), de dar-lhe voz em um contexto que pretende controle, domínio e aniquilação. Nas últimas páginas de Rua de mão única ${ }^{33}$ Benjamin defenderá, pensando na guerra - a que havia acontecido, mas também a que mais de dez anos depois eclodiria -, uma outra relação dos seres humanos com a natureza, não propriamente de domínio e tirania. Seria preciso, segundo ele, dominar esse domínio. Afinal, "Essa guerra é uma revolta da técnica que cobra em 'material humano' o que lhe foi negado pela sociedade." 34

Vale observar que à revolta da técnica, vista como segunda natureza, corresponde outra revolta: a das pulsões, da natureza interna aos seres humanos, que corre subterrânea e clandestina na história, tão brilhantemente interpretada, como se sabe, na Dialética do esclarecimento ${ }^{35}$. Observe-se, de passagem, que a obra escrita em conjunto por Theodor W. Adorno e Max Horkheimer muito deve a filosofia benjaminiana.

da fase do início, assim tampouco ela deixará atrás de si uma imagem permanente e insconscientemente conservada na memória. Por toda parte, em cada explosão, ela rompeu a barreira de proteção contra os estímulos, sobre a qual se forma a experiência, o intervalo de tempo entre o esquecimento salutar e a salutar recordação. A vida transformou-se em uma sucessão intemporal de choques, entre os quais se rasgam lacunas, intervalos paralisados. Contudo, nada seja mais funesto para o futuro do que o fato de que breve, literalmente, ninguém será mais capaz de pensar nisso, pois cada trauma, cada choque não superado, daqueles que retornam da guerra, é o fermento da futura destruição." (ADORNO, 1992, p. 46; 1997, p. 60) (Grifo meu, a.f.v.).

33 BENJAMIN, Walter. Einbahnstrase. Frankfurt: Suhrkamp, 1995.

34 BENJAMIN, 1993, op. cit., p. 196.

35 HORKHEIMER, M.; ADORNO, T. W. Dialektik der aufklärung: philosophische fragmente. GS, v. 3. Frankfurt aim maim: Suhrkamp, 1997; HORKHEIMER, M. Eclipse of reason. New York: Continuum, 1996. Sobretudo o capítulo 3. 


\section{História e modernidade: o progresso como palco de ruínas}

“A Tradição dos oprimidos nos ensina que o 'estado de exceção' em que vivemos é na verdade regra geral". (Tese VIII)

A partir das Teses, texto curto e de enorme densidade teórica, selecionei algumas idéias centrais da filosofia da história de Benjamin, que logo passarei a apresentar.

Antes disso vale dizer, em boa hora, que não considero que a filosofia benjaminiana, como aliás nenhuma outra, possa ser ontologizada. Não se pode também "utilizá-la" como um "instrumental aplicável", mas sim como interlocução do/no campo, um conjunto de idéias em aberto, que ajudem a continuar pensando. A própria obra de Benjamin nos ensina a repelir os fanatismos e as leituras aligeiradas, além de ser, como toda boa filosofia, não prescritiva.

De forma sumária, pode-se dizer que a crítica de Benjamin nas Teses escritas como "introdução" metodológica ao Trabalho das Passagens - dirigese a uma concepção de história presente tanto no historicismo quanto no marxismo vulgar. Benjamin entende que ambos compartilham de uma concepção linear de história, que tem no progresso técnico seu critério maior, creditando-lhe o estatuto de norma histórica (Tese VIII). Além disso, essa concepção cultiva uma empatia com o passado, de modo que os fatos históricos passam a ser justapostos em etapas de um desenvolvimento supostamente necessário. A esta concepção corresponde ainda a fetichização tecnológica do trabalho, bem como uma concepção utilitária de natureza, considerada sempre disponível e grátis (Tese XI).

Esta escritura histórica é triunfalista, dos vencedores. Ao pretender-se universal e absoluta, recalca os desejos não concretizados, fazendo esquecer as esperanças que ficaram para trás. Ela advoga - como aliás o faz também na tradição hegeliana - uma racionalidade necessária.

A esta concepção Benjamin opõe um outro conceito de história, uma vez que

Todos que até hoje venceram participam do cortejo triunfal, em que os dominadores de hoje espezinham os corpos do que estão prostrados no chão. Os despojos são carregados no cortejo, como de praxe. Estes despojos são os chamados bens culturais. O materialista histórico os contempla com distanciamento. Pois todos os bens culturais que ele vê têm uma origem sobre a qual ele não pode refletir sem horror. Devem seus esforços não somente ao esforço dos grandes gênios que os criaram, como à corvéia anônima dos seus contemporâneos. Nunca houve um documento de cultura que não fosse também um 
documento de barbárie. E assim como a cultura não é isenta de barbárie, não o é, tampouco, o processo de transmissão da cultura. Por isso, na medida do possível, o materialista histórico se desvia dela. Considera sua tarefa escovar a história a contrapelo. ${ }^{36}$

Ora, uma historiografia que possa ser crítica, deve sim, como é evidente, lançar seu olhar ao passado, mas não no sentido de constituir uma história universal (Tese XVII) ou uma imagem eternizada do que passou (Teses VI e $\mathrm{XVI})$. Ao contrário, o passado só fará sentido se for repleto de agoridade (Jetzzeit), atualizado. O olhar histórico se volta para o passado para fazer ressurgir as esperanças não concretizadas, já que a história é (pelo menos também) um palco de catástrofes, de escombros.

Minhas asas estão prontas para o vôo,

Se pudesse, eu retrocederia

Pois eu seria menos feliz

Se permanecesse imerso no tempo vivo.

Gerhard Scholem, Saudação do Anjo

Há um quadro de Klee que se chama Angelus Novus. Representa um anjo que parece querer afastar-se de algo que ele encara fixamente. Seus olhos estão escancarados, sua boca dilatada, suas asas abertas. O anjo da história deve ter esse aspecto. Seu rosto está dirigido para o passado. Onde nós vemos uma cadeia de acontecimentos, ele vê uma catástrofe única, que acumula incansavelmente ruína sobre ruína e as dispersa aos nossos pés. Ele gostaria de deter-se para acordar os mortos e juntar os fragmentos. Mas uma tempestade sopra do paraíso e prende-se em suas asas com tanta força que ele não pode mais fechá-las. Essa tempestade o impele irresistivelmente para o futuro, ao qual ele vira as costas, enquanto o amontoado de ruínas cresce até o céu. Essa tempestade é o que chamamos progresso. ${ }^{37}$

Contar a história do ponto de vista dos vencidos significa, portanto, paralisar o tempo, explodir o continuum da história. Só o presente paralisado pode perceber seu conteúdo pretérito, e por isso nadar contra a corrente. Esta é uma história que não se dirige ao passado como elenco de acontecimentos, nem ao futuro como progresso infinito, mas busca na cesura do presente iden-

36 BENJAMIN, 1993, op. cit., p. 225; 1977, op. cit., p. 254 (Tradução ligeiramente modificada).

37 BENJAMIN, 1993, op. cit., p. 226; 1977, op. cit., p. 255. 
tificar aquilo que poderia ter sido. Daí a importância fundamental do trabalho da memória, da reminiscência. Tarefas do melancólico, do narrador ${ }^{38}$.

Ao contrário do que pensa uma historiografia contemplativa, os fatos passados que devem ser citados no tribunal da história não são aqueles que devem servir de exemplo para nossas ações presentes e futuras. Do passado é preciso reter as lembranças daquilo que não foi realizado, das esperanças não cumpridas da história, dos desejos que ficaram.

\section{Ainda progresso e história: uma notinha para a historiografia dos esportes}

As críticas de Benjamin à concepção de tempo histórico homogêneo e vazio, e que tem como mote o progresso infinito, podem nos ajudar a pensar algumas questões relacionadas ao esporte e a escritura de sua história.

O esporte é um dos principais vetores da idéia de um progresso linear e infinito, cuja concepção de natureza é fortemente vinculada à produtividade e à tecnificação. As metáforas maquinais em relação ao corpo, tão típicas da modernidade, não são figuras de linguagem inocentes ${ }^{39}$.

Talvez por isso ainda prepondere uma história por vezes bastante celebrativa dos "feitos" esportivos, que desconsidera a dialética entre progresso e regressão. O esporte é um campo privilegiado onde o progresso é considerado como "[...] um processo sem limites, idéia correspondente à da perfectibilidade infinita do gênero humano", conforme se lê sobre o dogmatismo da social-democracia dos anos trinta ${ }^{40}$.

À direita e à esquerda há uma história do esporte que louva a dominação irrestrita do corpo. Há uma história do olimpismo, muito presente, que não

38 Dois temas muito importantes para a teoria da história em Walter Benjamin ficaram, em razão dos limites desse trabalho, relegados para uma outra exposição. Um deles é o da narração, o outro é o surpreendente significado que a revolução tem para Benjamin, não como aceleração do tempo, como queria (e quer?) um marxismo mais ortodoxo, mas como sua paralisação!

39 Desenvolvo essas idéias em vários trabalhos, entre eles VAZ, A. F. Treinar o corpo, dominar a natureza: notas para uma análise do esporte com base no treinamento corporal. In: SOARES, C. L. Corpo e eduacação. Campinas: Unicamp, 1999. (Cadernos CEDES, 48); e VAZ, A. F. Do culto à performance: esporte, corpo e rendimento. Revista Brasileira de Ciências do Esporte, v. 21, n. 1, 1999.

40 BENJAMIN, 1993, op. cit., p. 229. 
quer sequer pensar na hipótese de que os Jogos de Berlim em 1936 talvez não tenham sido uma "traição" aos ideais olímpicos, mas, pelo contrário, sua afirmação ${ }^{41}$.

Há um caráter restaurativo no Olimpismo, que por um lado cria a fantasia da continuidade entre os Jogos da Antigüidade grega e da Modernidade, e por outro procura um último suspiro para os ideais aristocráticos, feridos, um século antes da instituição das Olimpíadas Modernas, pela Revolução Francesa. Esse caráter restaurativo é mais do que confirmado pela equiparação (mitológica!) entre os mitos gregos e os germânicos, vinculados à supremacia racial, fortes Leitmotiven dos Jogos de 1936. A Obra de Arte Total (Gesamtkunstwerk) em que se constituíram as Olimpíadas de Berlin teve sua face cinematográfica notavelmente construída no projeto Olympia (Festa da Beleza e Festa do Povo), dirigido pela talentosa Leni Riefensthal, cineasta oficial do Terceiro Reich.

Esta história considera o progresso de forma contemplativa, sem observar seu potencial também regressivo. Não vê que todo documento de cultura também o é de barbárie; que a transmissão cultural também é portadora de violência (Tese VII); que "há sangue na sapatilha", como Heiner Müller ${ }^{42}$ lembra a Pina Bauch, e que isso não pode ser simplesmente louvado.

Esta é uma historiografia que, também no mundo acadêmico, constrói os museus que louvam as conquistas no esporte, como se fossem elas conquistas da humanidade.

Gostaria de ver com mais força na Educação Física/Ciências do Esporte uma historiografia que escovasse a história a contrapelo, que concorresse com a história celebrativa e pudesse narrar os acontecimentos passados também do ponto de vista dos vencidos.

É preciso dizer, no entanto, que isso não significa desconsiderar o caráter dialético das práticas corporais (e do esporte em especial), o que seria pouco rigoroso com a história, talvez apenas exercício de preconceito.

Não é o caso, também, de se advogar uma "história militante", que procure por vilões e mocinhos, mas de se considerar que também há fissuras, fracassos e feridas que não cicatrizarão se permanecerem desprezadas. É preciso lembrar, não para que se possa esquecer, mas para que o passado seja retrabalhado, compreendido. Se não for assim, as feridas reaparecerão violentamente, na forma de trauma, como tudo aquilo que é recalcado.

41 ALKEMEYER, T. Körper, kult und politik. Von der 'muskelreligion' Pierre de Coubertins zur inszenierung der macht in den Olympischen Spielen von 1936. Frankfurt, 1996.

42 MÜLLER, H. Blut ist im schub oder das rätsel der freiheit. Heiner Müller material. Texte und kommentare. Leipzig: Reclam, 1990. 


\section{REFERÊNCIAS}

ADORNO, T. W. Minima Moralia: reflexionen aus der beschädigten leben. GS, v. 4. Frankfurt am Main: Suhrkamp, 1997.

- Minima Moralia: reflexões a partir da vida danificada. Tradução de Luiz Eduardo Bicca. São Paulo: Ática, 1992. Original alemão.

ALKEMEYER, Thomas. Körper, kult und politik. Von der 'Muskelreligion' Pierre de Coubertins zur Inszenierung der Macht in den Olympischen Spielen von 1936. Frankfurt, 1996.

ARENDT, Hannah. Water Benjamin: 1892-1940. In: Men in dark times. Tradução de Harry Zohn. Harmondsworth: Pelican, 1973. Original alemão.

BENJAMIN, Walter. Über kinder, jugend und erziehung (mit abbildungen aus der Sammlung Benjamin). Frankfurt: Suhrkamp, 1969.

A modernidade. In: A modernidade e os modernos. Tradução de Heindrun Krieger Mendes da Silva, Arlete de Brito e Tania Jatobá. Rio de Janeiro: Tempo Brasileiro, 1975. (Biblioteca Tempo Universitário, 41).

Über den begriff der geschichte. In: Iluminationen. (Ausgewählte schriften 1). Frankfurt: Suhrkamp, 1977.

. Moskauer tagebuch. Frankfurt: Suhrkamp, 1980a.

. Das kunstwerk im zeitalter seiner technischen reproduzierbarkeit (Erste Fassung). In: TIEDEMANN, Rolf; SCHWEPPENHÄUSER, Hermann (Org.). Gesammelte Schriften. Frankfurt: Suhrkamp, 1980.

- Sobre o conceito de História. In: ROUANET, Sérgio Paulo (Org.). Magia e técnica, arte e política: ensaios sobre literatura e história da cultura. Tradução de Sérgio Paulo Rouanet. 6. ed. São Paulo: Brasiliense, 1993. Original alemão.

. Einbahnstrase. Frankfurt: Suhrkamp, 1995.

BERMAN, Marshall. Tudo que é sólido desmancha no ar: a aventura da modernidade. Tradução de Carlos Felipe Moisés e Ana Maria L. Ioriatti. São Paulo: Companhia da Letras, 1992. Original alemão.

BRECHT, Bertold. Schriften zur politik und gesellschaft (Gesammelte Werke 20). Frankfurt: Suhrkamp, 1967.

BUCK-MORSS, Susan. Dialektik des Sehens: Walter Benjamin und das PassagenWerk. Tradução de Joachim Schulte. Frankfurt: Suhrkamp, 1993. Original inglês.

ESPERANÇA, Ilma. O cinema operário na República de Weimar. São Paulo: UNESP, 1993. 
FULD, Werner. Walter Benjamin. Eine biografie. Reinbeck bei Hamburg: Rowohlt, 1990.

GAGNEBIN, Jeanne-Marie. Walter Benjamin: os cacos da História. Tradução de Sônia Salzstein. 2. ed. São Paulo: Brasiliense, 1993.

Anexo: Walter Benjamin, um "estrangeiro de nacionalidade inderteminada, mas de origem alemã”. In: SELIGMANN-SILVA, Márcio (Org.). Leituras de Walter Benjamin. São Paulo: Fapesp/Annablue, 1999.

HABERMAS, Jürgen. Soziologische notizen zum verhältnis von arbeit und freizeit. In: PLESSNER, H.; BOCK, H.-E.; GRUPE, O. (Org.). Sport und leibeserziehung. Munique, 1967.

. Crítica conscientizante ou salvadora - A atualidade de Walter Benjamin. In: FREITAG, Barbara; ROUANET, Sérgio Paulo (Org.). Habermas. 2. ed. São Paulo: Ática, 1990. (Coleção Grandes Cientistas Sociais, 15).

HORKHEIMER, Max. Eclipse of reason. New York: Continuum, 1996.

HORKHEIMER, Max; ADORNO, Theodor W. Dialektik der aufklärung: philosophische fragmente. GS, v. 3. Frankfurt am Main: Suhrkamp, 1997.

LÖWY, Michael. Distante de todas as correntes e no cruzamento dos caminhos: Walter Benjamin. In: . Redenção e utopia: o judaísmo libertário na Europa Central (um estudo de afinidade eletiva). Tradução de Paulo Neves. São Paulo: Companhia das Letras, 1989.

MATOS, Olgária Chain Féres. Desejo de evidência, desejo de vidência: Walter Benjamin. In: NOVAES, Adauto. $O$ desejo. 2. ed. São Paulo: Companhia das Letras, 1990. p. 283-306.

MÜLLER, Heiner. Blut ist im schub oder das rätsel der freiheit. Heiner Müller material. Texte und kommentare. Leipzig: Reclam, 1990.

. Há sangue na sapatilha ou o enigma da liberdade. Tradução e Introdução de José Galisi Filho. Cultura Vozes, n. 2, p. 7-11, mar./abr. 1995.

PILZ, Gunter. Sociologia do esporte na Alemanha. Tradução e Notas de Alexandre Fernandez Vaz. Estudos Históricos, n. 23, 1999.

PLESSNER, Helmut. Die funktion des sports in der industriellen gesellschaft. Wissenschaft und Weltbild, n. 19, p. 262-274, 1956.

SONTAG, Susan. Introduction. In: BENJAMIN, Walter. One-way street and other writings. Nova York, 1997.

TIEDEMANN, Rolf (Org.). Aufklärung für kinder: rundfunkvorträge. Frankfurt: Suhrkamp, 1985. 
WILDMANN, Daniel. Begehrte körper: konstruktion und inszenierung des "arischen" männerkörpers im "Drittenreich”. Würzburg: Königshausen \& Neumann, 1998.

VAZ, Alexandre Fernandez. Razão e corporeidade: elementos para a compreesão da cultura corporal na modernidade. Florianópolis, 1995. Dissertação (Mestrado) - Programa de Pós-Graduação em Educação, CED/Universidade Federal de Santa Catarina.

- Treinar o corpo, dominar a natureza: notas para uma análise do esporte com base no treinamento corporal. In: SOARES, Carmen Lúcia. Corpo e Educação. Campinas: Unicamp, 1999. (Cadernos CEDES, 48).

. Do culto à performance: esporte, corpo e rendimento. Revista Brasileira de Ciências do Esporte. v. 21, n. 1, 1999.

. Em favor da memória, contra o esquecimento: História, progresso e esporte em Walter Benjamin. CONGRESSO BRASILEIRO DE HISTÓRIA DA EDUCAÇÃO FÍSICA, ESPORTE, LAZER E DANÇA, 7., 2000, Porto Alegre. Anais e Resumos. Porto Alegre: Universidade Federal do Rio Grande do Sul, 2000. p. 186-192. 